CERN-PPE/97-11

4 February 1997

\title{
BULK DAMAGE EFFECTS IN IRRADIATED SILICON DETECTORS DUE TO CLUSTERED DIVACANCIES
}

\author{
K. Gill \\ CERN, CH-1211, Geneve 23, Switzerland. \\ G. Hall, B. MacEvoy \\ Blackett Laboratory, Imperial College, London SW7 2AZ, UK.
}

\begin{abstract}
High resistivity silicon particle detectors will be used extensively in experiments at the future CERN Large Hadron Collider where the enormous particle fluences give rise to significant atomic displacement damage. A model has been developed to estimate the evolution of defect concentrations during irradiation and their electrical behaviour according to Shockley-Read-Hall (SRH) semiconductor statistics. The observed increases in leakage current and doping concentration changes can be described well after gamma irradiation but less well after fast neutron irradiation. A possible non-SRH mechanism is considered, based on the hypothesis of charge transfer between clustered divacancy defects in neutron damaged silicon detectors. This leads to a large enhancement over the SRH prediction for $\mathrm{V}_{2}$ acceptor state occupancy and carrier generation rate which may resolve the discrepancy.
\end{abstract}




\section{INTRODUCTION}

High resistivity silicon detectors will be used extensively in experiments 1,2 at the CERN Large Hadron Collider (LHC) where intense proton beams will be collided with a total centre of mass energy of $14 \mathrm{TeV}$ at a rate of $40 \mathrm{MHz}$. High interaction rates are essential to accumulate sufficient numbers of the rare events from which new physics discoveries are expected and these lead to large numbers of penetrating charged particles traversing the inner layers of the experiments. Highly segmented silicon detectors, widely used in present particle physics experiments, will be employed to measure their trajectories and, in consequence, are exposed to high levels of radiation, typically $10 \mathrm{Mrad}$ and $10^{14} \mathrm{~cm}^{-2}$ fast neutron equivalent over the operational lifetime.

High resistivity material is used for particle detectors to allow full depletion at moderate bias voltages (<200V) (for a recent review see Ref. 3). Although many changes take place during and after irradiation, for example at the surface of microstrip detectors, studies over recent years have shown that up to $\sim 10^{14}$ particles $/ \mathrm{cm}^{2}$ most do not cause fundamental problems.4-9 The principal obstacle to long term operation of silicon detectors at LHC arises from bulk damage which alters the effective doping, and thus operational voltage, of the material.

Although radiation damage studies have been carried out on silicon for many years, the microscopic origin of effects observed is still not well understood. Phenomenological models have been developed ${ }^{10}$ which have been adequate for many applications but provide no guidance in interpreting, or modifying, the behaviour of high resistivity detector material. Recently, it has been hypothesised ${ }^{11}$ that many observations on detector material could be attributed to a few deep traps introduced during irradiation and, using methods developed for optical absorption studies, 12 the evolution of important traps could be modelled numerically. ${ }^{13}$ This has allowed the tentative identification of a few states which might explain the most significant observations.

In comparing the results from the model with experimental data, it was found that, while gamma irradiation results can be predicted rather well, there is a large discrepancy in the description of fast neutron $(\sim 1 \mathrm{MeV})$ damage. The major difference between the damage caused by these two types of particles is in the formation by neutrons of local highly disordered regions, referred to as clusters, which contain multiple defects. This paper proposes a possible explanation for resolving the discrepancy which is attributed to charge exchange between divacancies $\left(\mathrm{V}_{2}\right)$ contained inside the clusters. Both effective doping concentration under bias and leakage (dark) current can be enhanced by a large 
factor over the standard Shockley-Read-Hall (SRH) prediction as a result of this mechanism.

Section II of this paper reviews the bulk (displacement) damage mechanisms, experimental results for silicon detectors, and the model developed to explain the experimental data. Attention is focused on leakage current damage and the apparent discrepancy between the model and data. Section III considers the possible effects of clustering of divacancy states, hypothesised to occur after neutron damage. Calculations of the charge exchange reactions between neighbouring $V_{2}$ states are presented, which result in a large increase in charged $V_{2}$ concentration and a related, large increase in the leakage current density contributed by $\mathrm{V}_{2}$ states.

\section{BULK RADIATION DAMAGE IN SILICON}

\section{A. Bulk damage mechanisms}

Bulk damage occurs when incident particles transfer sufficient kinetic energy to the lattice to displace a silicon atom from its lattice site; around $15 \mathrm{eV}$ of recoil energy is required. ${ }^{14}$ Displaced atoms may come to rest in interstitial (I) positions, leaving vacancies (V) at their original locations. If the recoiling atom has sufficient kinetic energy it can displace further silicon atoms, giving rise to a cascade of displacements. Some resulting vacancies and interstitials recombine, leaving no net damage, while some vacancies may amalgamate to form stable divacancies. The remaining vacancies and interstitials diffuse away from the damaged region until they reach a surface or react with other defects, forming defect complexes, or react with impurity atoms such as carbon, oxygen and phosphorus, which are among the more common impurities in typical detector grade silicon.

The dependence of damage on particle type and energy has been widely correlated with Non-Ionising Energy Loss 15 (NIEL) and this seems to be in general agreement with observations. However, there are significant differences between the type of damage created by light particles (photons and low energy electrons) and heavy particles (e.g. protons, neutrons and pions).

In the case of gamma irradiation, for example ${ }^{60}$ Co photons $(1.17$ and $1.33 \mathrm{MeV})$, bulk damage occurs primarily as a result of the interactions of Compton electrons with the host atoms. ${ }^{16}$ The scattered electrons from ${ }^{60}$ Co photons typically have energies of only a few hundred $\mathrm{keV}$ on average, 17 which is insufficient to displace more than one or two silicon atoms $^{18}$ from their lattice positions. The generation of divacancy states is therefore limited and most defects are of the vacancy-impurity type distributed uniformly throughout the 
bulk silicon. The introduction rates for vacancies and divacancies have been determined as $\eta_{\mathrm{V}}=1.2 \times 10^{-3} \mathrm{~cm}^{-1}$ and $\eta_{\mathrm{V}_{2}}=2.8 \times 10^{-5} \mathrm{~cm}^{-1}$ respectively $( \pm 10 \%)$ for ${ }^{60} \mathrm{Co}$ photon damage. ${ }^{19}$

In contrast, $1 \mathrm{MeV}$ neutrons are much more damaging as up to $130 \mathrm{keV}$ is transferred to the primary knock-on atom (PKA). For recoil energies around $100 \mathrm{keV}$, typically $50 \%$ is deposited via ionisation ${ }^{20}$ while displacements predominate as the knock-on atoms lose their final $5-10 \mathrm{keV}$. As the atoms reach the end of their range, the distance between collisions is similar to the atomic separation and vacancies and interstitials tend to be created in dense clusters. Simulations have shown that, for $1 \mathrm{MeV}$ neutrons incident upon silicon, a tree-like displacement cascade is usually created with two or three "terminal clusters" of $\sim 50 \AA$ linear dimension. 21,22 At least $90 \%$ of the initial V-I pairs recombine immediately and some vacancies combine to form $V_{2}$, and possibly larger vacancy complexes. The remaining vacancies and interstitials diffuse away and are eventually trapped forming stable defects distributed evenly throughout the substrate. The introduction rates for vacancies and divacancies have been determined to be $\eta_{\mathrm{V}}=$ $2.1 \pm 0.5 \mathrm{~cm}^{-1}$ and $\eta_{\mathrm{V}_{2}}=4.7 \pm 0.4 \mathrm{~cm}^{-1}$ respectively for $1 \mathrm{MeV}$ neutron damage. ${ }^{23}$

The ratio of introduction rates for divacancies relative to vacancies is therefore $\sim 100$ times greater for neutron damage than for ${ }^{60} \mathrm{Co}$ photon damage. The main difference between the gamma and neutron bulk damage mechanisms is the formation of defect clusters with neutron damage. For neutron damage, most of the displacements occur in the formation of the damage clusters, therefore these small volumes are expected to be rich in divacancy states. There is strong evidence that $V_{2}$ defects are formed by the combination of vacancies created in close proximity as opposed to the coupling of migrating vacancies from the displacement events of different incident particles 24,25 and theoretical calculations of defect cluster formation in radiation damaged silicon 26,27 predict a core of divacancies in the damage cluster (some of which may coalesce to form four-vacancy complexes ${ }^{27}$ ).

\section{B. Bulk damage effects}

The principal observable consequences of bulk damage in silicon detectors are increased leakage currents and doping changes. Diode leakage currents increase in linear proportion to particle fluence. After high energy hadron irradiation the volumetric current density JV increases with fluence $\Phi$ as $\mathrm{J}_{\mathrm{V}}=\alpha \Phi$, with $\alpha \AA 5-10 \times 10^{-17} \mathrm{~A} / \mathrm{cm}\left(\right.$ at $\left.20^{\circ} \mathrm{C}\right) ; 4,5,28$ the damage constant for ${ }^{60} \mathrm{Co}$ photons is much smaller, $\alpha \AA 7 \times 10^{-23} \mathrm{~A} / \mathrm{cm}\left(\right.$ at $\left.20^{\circ} \mathrm{C}\right) .{ }^{29}$ Although the linear dependence is apparently trivial, it is not easy to explain. Annealing effects are important; leakage currents are observed to decrease by factors of 2-3 during long term room temperature annealing. ${ }^{30}$ The current is sensitive to temperature and can be reduced 
considerably by modest cooling. The dependence is usually parameterised as $\mathrm{JV}_{\mathrm{V}} \sim \mathrm{T}^{2} \exp (-$ $\mathrm{E}_{\mathrm{a}} / \mathrm{kT}$ ) with $\mathrm{E}_{\mathrm{a}} \AA 0.62 \mathrm{eV}$ for neutron damage, 31,32 and $\mathrm{E}_{\mathrm{a}} \AA 0.68$ for ${ }^{60}$ Co gamma damage. ${ }^{33}$

During irradiation there are changes in the effective doping concentration $\mathrm{N}_{\text {eff }}$ of the bulk material. After a sufficient fluence of heavy particles, the bulk silicon, which is normally ntype, is observed to invert and behave as p-type, when under reverse bias.5,8,9 A typical fluence of $1 \mathrm{MeV}$ neutrons to bring this about is $\Phi_{\text {inv }} \sim 2 \times 10^{13} \mathrm{~cm}^{-2}$; more detailed studies $^{34}$ as a function of starting material resistivity have parameterised the dependence on initial doping concentration $\mathrm{N}_{0}$ as $\Phi_{\text {inv }} \AA 18[\mathrm{~cm}] \times \mathrm{N}_{0}$. Both short and long term annealing is observed. At ambient temperature there is an initial recovery of donors (or acceptor reduction) but later a slow increase of acceptor density is observed ("antiannealing"). 28 The effect is especially marked after high fluence irradiations. Cooling to below about $5^{\circ} \mathrm{C}$ has been observed to suppress anti-annealing but at the expense of the initial beneficial anneal, during which some of the damage is apparently repaired. This has been established by experiment 28,35 but there is no theoretical explanation.

The changes in the effective doping concentration are attributed to the build-up of charged defect states in the silicon substrate. Several radiation induced defects in silicon have been identified and measured in silicon using different techniques such as infra-red absorption, electron paramagnetic resonance (EPR), photoconductivity and deep level transient spectroscopy (DLTS). This has enabled the determination of trap energy levels, charge states and introduction rates. Table I shows the defects considered to be most important 13 in irradiated high resistivity silicon detectors.

\section{Microscopic explanation of bulk damage}

\section{Simulation of the evolution of defect concentrations}

The numerical model of complex defect evolution was originally developed by Davies and co-workers to explain optical absorption data at infra-red wavelengths after irradiation by $2 \mathrm{MeV}$ electrons. ${ }^{12}$ Characteristic absorption lines correspond to the presence of known defect centres and the concentrations of several species were determined as a function of electron fluence using samples of Czochralski and float-zone material, where initial impurity concentrations had been accurately determined. The model required some modifications to be applicable to high resistivity detector material, in particular to include the presence of phosphorus. The reactions used in the model are listed in Table II. 
Reaction rates are controlled by the concentration of impurities and defects and their capture radii. Vacancies are principally captured by oxygen whose concentration is high $\left(\sim 10^{15} \mathrm{~cm}^{-3}\right)$ compared to the phosphorus dopant $\left(\sim 10^{12} \mathrm{~cm}^{-3}\right)$. High carbon concentrations $\left(\sim 10^{15} \mathrm{~cm}^{-3}\right)$ provide the major sink for interstitials. The measured introduction rates of interstitials, vacancies and primary divacancies are then used to predict defect concentrations in high resistivity detector material during neutron and gamma irradiation. Fig. 1 shows how the different defect species evolve as a function of ${ }^{60}$ Co gamma dose and $1 \mathrm{MeV}$ neutron fluence. The uncertainties in the predicted concentrations are at the level of $\sim 40 \%$, arising mainly from errors on primary introduction rates, the concentrations of oxygen and carbon, and uncertainties in the ratios of capture radii.

\section{Deep acceptor model}

A numerical estimate of defect concentrations is one essential piece of information to construct a model. A second is the application of semiconductor physics to predict the consequences of traps, particularly the deep levels. This usually follows the ideas of Shockley, Read and Hall 36,37 which are briefly summarised.

Most deep levels have two charge states, so an acceptor is negatively charged when occupied by an electron and neutral when empty, while a donor is positively charged when unoccupied but neutral otherwise. In unbiased material, where thermal equilibrium holds, the occupation of a state depends on Fermi-Dirac statistics and is calculable if the concentration of states and their energy levels are known. In biased material the charge state depends on the trap energy level but also on the density of free carriers. It is necessary to solve Poisson's equation for the electric field, satisfy current continuity conditions and include correct occupancy statistics, which usually makes numerical solution essential.

In thermal equilibrium, emission and capture rates of electrons (or holes) are identical. This detailed balance allows the calculation of the emission rate probability of a trap by the use of Fermi-Dirac occupancy statistics. In a silicon diode under reverse bias the system is in a steady state away from thermal equilibrium. It is assumed that emission rate probabilities calculated under thermal equilibrium conditions remain unchanged allowing the steady state trap occupancy to be written as

$$
f=\frac{\sigma_{p} n_{i} e^{-\beta}+\sigma_{n} n}{\sigma_{n}\left(n_{i} e^{\beta}+n\right)+\sigma_{p}\left(n_{i} e^{-\beta}+p\right)} \quad \text { with } \quad \beta=\frac{E_{t}-E_{i}}{k T}
$$


$\mathrm{n}_{\mathrm{i}}$ is the intrinsic carrier concentration, $\mathrm{n}$ and $\mathrm{p}$ are the electron and hole concentrations, $\sigma_{\mathrm{n}}$ and $\sigma_{\mathrm{p}}$ are the trap cross-sections, the trap energy level is $E_{t}$, the intrinsic level is $E_{i}$, and $\mathrm{kT}$ is the Boltzmann factor. Under reverse bias, capture reactions are suppressed due to the reduction of mobile carrier densities and leakage currents arise from emission processes. The carrier generation rate is then given by

$$
G=\frac{N_{t} \sigma_{n} \sigma_{p} v\left[n_{i}^{2}-n p\right]}{\sigma_{n}\left(n_{i} e^{\beta}+n\right)+\sigma_{p}\left(n_{i} e^{-\beta}+p\right)}
$$

where $\mathrm{N}_{\mathrm{t}}$ is the trap concentration and $\mathrm{v}$ is the thermal carrier velocity.

If the occupancy of each trap is known, the effective doping concentration $\mathrm{N}_{\text {eff, }}$ (positive for n-type) can be calculated from

$$
N_{\text {eff }}=\sum_{D}\left(1-f_{D}\right) N_{D}-\sum_{A} f_{A} N_{A}+p-n
$$

by summing over the donors (D) and acceptors (A), where $\mathrm{N}_{\mathrm{A}}$ and $\mathrm{N}_{\mathrm{D}}$ are the trap concentrations, in addition to the free carriers in the bulk (n and p).

Calculations of the evolution of $\mathrm{N}_{\text {eff }}$ were first carried out by Watts and co-workers. ${ }^{23}$ They hypothesised, to simplify, that after high particle fluences bulk silicon was intrinsic and assumed a single acceptor level at the middle of the energy gap. Both assumptions are justified by experimental data, since highly irradiated silicon does seem to become almost intrinsic in thermal equilibrium, while under bias it behaves as strongly p-type. Using the measured value of current density, they calculated the depletion voltage, and thus effective doping concentration, as a function of neutron fluence. There was only one free parameter, the introduction rate of the acceptor state, which was adjusted to match the data. Given the simplicity of the assumptions, it was possible to explain the observed behaviour of silicon diodes constructed on both p-type and n-type substrates after neutron irradiation surprisingly well. If the acceptor is not at mid-gap, the required introduction rate can be plotted as a function of the trap energy level ${ }^{13,29}$ as in Fig. 2.

The essence of the deep acceptor hypothesis was verified by studying the depletion behaviour of silicon photodiodes under illumination. ${ }^{13}$ Irradiated detectors were observed to behave in a manner consistent with deep level acceptor states being filled by photogenerated electrons, in contrast to unirradiated devices. 
An attempt has been made to ascertain which defect states might be responsible for the observed effects of bulk damage in high resistivity silicon. In Fig. 2 the divacancy-oxygen $\left(\mathrm{V}_{2} \mathrm{O}\right)$ defect complex 38,39 is identified as the most probable candidate to explain the change in effective doping concentration with neutron fluence. It is relatively close to the centre of the band gap, at an energy of $\mathrm{E}_{\mathrm{c}}-0.50( \pm 0.05) \mathrm{eV}$ and has an introduction rate, according to the simulation, of around $1 \mathrm{~cm}^{-1}$ for $1 \mathrm{MeV}$ neutrons.

To test the model for ${ }^{60}$ Co gamma damage several high resistivity silicon photodiodes were irradiated. These devices were manufactured by SINTEF, 40 each had an active area of $5 \times 5 \mathrm{~mm}^{2}$ and a thickness of $300 \mu \mathrm{m}$. The initial phosphorus concentration was determined by capacitance-voltage $(\mathrm{C}-\mathrm{V})$ measurements to be $5.5 \times 10^{11} \mathrm{~cm}^{-3}$ in the devices tested. According to photoluminescence studies, there was no significant compensation due to boron. The devices were irradiated unbiased, at room temperature using the ${ }^{60} \mathrm{Co}$ source at Imperial College. The dose rate was typically $200 \mathrm{krad} / \mathrm{hr}$, measured with a calibrated photodiode accurate to $\sim 10 \%$.

The change in $\mathrm{N}_{\text {eff }}$ (absolute value) with dose is shown in Fig. 3, along with results from the bulk damage model explained below. The effective doping starts $n$-type but inverts to p-type at around 90Mrad $\left(9 \times 10^{5} \mathrm{~Gy}\right)$, with the data points determined from $\mathrm{C}-\mathrm{V}$

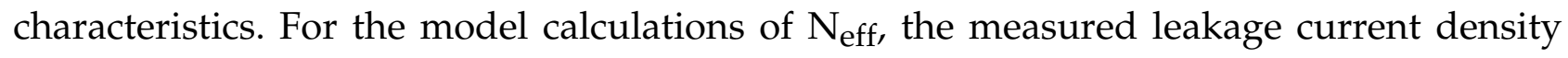
was used as an input parameter to determine the steady state free carrier concentrations ( $\mathrm{n}$ and p) from the current continuity equation. According to the model the creation of $\mathrm{V}_{2} \mathrm{O}$ and VP defects dominates the change in $\mathrm{N}_{\text {eff }}$ with gamma irradiation. $\mathrm{E}\left(\mathrm{V}_{2} \mathrm{O}\right)$ is not precisely known $\left(\mathrm{E}_{\mathrm{c}}-0.50 \pm 0.05 \mathrm{eV}\right)$ and within this uncertainty range the model results can be influenced significantly. Good agreement with the data was obtained with $E\left(V_{2} O\right)=E_{c^{-}}$ $0.515 \mathrm{eV}$ and this value was subsequently used in the other calculations.

A similar comparison was made between the model prediction for the change in $\mathrm{N}_{\text {eff }}$ and data for devices irradiated with $1 \mathrm{MeV}$ neutrons. Several Micron 41 photodiodes $\left(10 \times 10 \mathrm{~mm}^{2}, 250 \mu \mathrm{m}\right.$ thickness) were irradiated at the RAL facility, ${ }^{42}$ with a flux of around $5 \times 10^{12} \mathrm{n} / \mathrm{cm}^{2} / \mathrm{hr}$. Dosimetry was carried out using the activated foil technique, which has a systematic uncertainty of $\sim 20 \% .42$ The measured change in $\mathrm{N}_{\text {eff }}$ is shown in Fig. 4, along with the model prediction. In these devices the initial phosphorus concentration was determined to be $\sim 10^{12} \mathrm{~cm}^{-3}$ and type inversion was observed to occur after a fluence of $\sim 2 \times 10^{13} \mathrm{n} / \mathrm{cm}^{2}$. In contrast to the gamma damage results, the model did not predict the observed change in $\mathrm{N}_{\text {eff }}$ as accurately; in particular, the inversion fluence was a factor of $\sim 3$ too high.

\section{Leakage currents in bulk damaged silicon detectors.}


Although the trap occupancies were derived in the model from experimentally measured values of leakage currents, they should lead to a self-consistent estimation of the leakage current density $\mathrm{J}_{\mathrm{V}}$ since,

$$
J_{v}=e G
$$

In the following calculations all defects are treated as single-level states; although three $\mathrm{V}_{2}$ energy levels are present in the band gap, the singly charged acceptor state at $\mathrm{E}_{\mathrm{c}}-0.42 \mathrm{eV}$ dominates the $\mathrm{V}_{2}$ occupancy under typical reverse biased conditions. In general, the electron and hole capture cross sections are not very well known for any of the defects considered. A value of $\sigma_{\mathrm{n}}=\sigma_{\mathrm{p}}=10^{-15} \mathrm{~cm}^{2}$ is therefore assumed which corresponds approximately to the cross-sectional area of a single atom and thus the typical size of a point-like defect in the bulk. Under the assumptions that $\mathrm{n}, \mathrm{p}<<\mathrm{n}_{\mathrm{i}}$ in a detector under reverse bias and that $\sigma_{\mathrm{n}}=\sigma_{\mathrm{p}}=\sigma$, equation (2) can be further simplified to

$$
G=\frac{N_{t} \sigma v n_{i}}{e^{\beta}+e^{-\beta}}=\frac{N_{t} \sigma v n_{i}}{2 \cosh (\beta)}
$$

The $\cosh (\beta)$ factors for the different defects in the model are shown in Table I. For similar trap concentrations, states near the centre of the band-gap are expected to contribute most to the leakage current. If a single trap dominates, equations (5) and (6) also predict the temperature dependence of the leakage current if the trap energy level is known.

Measurements of the leakage current were made on each detector at a bias voltage of $100 \mathrm{~V}$ which ensured that the diodes were fully depleted. The leakage current density was then obtained by dividing the current by the active volume of the device. All the devices included guard rings to ensure that the active volume was well defined. Table III shows the calculated contributions to the leakage current density after a dose of $100 \mathrm{Mrad}{ }^{60} \mathrm{Co}$ photons, compared to the data value (for $\mathrm{T}=300 \mathrm{~K}$ ). $\mathrm{V}_{2} \mathrm{O}$ states are predicted to be almost completely responsible for the increase in leakage current for ${ }^{60} \mathrm{Co}$ damage. Fig. 5 compares the model results with the measured data for doses up to 220Mrad. The model predicts a current density within a factor of 3 of the measured values which represents rather good agreement given the uncertainties. The temperature dependence of $J_{V}$ predicted by the model was also compared with data. Using the parameterisation $\mathrm{J}_{\mathrm{V}} \sim$ $\mathrm{T}^{2} \exp \left(-\mathrm{E}_{\mathrm{a}} / \mathrm{kT}\right)$ and taking into account the change in the band-gap energy with temperature, 43 the model predicted a value of $\mathrm{E}_{\mathrm{a}}=0.64 \mathrm{eV}$. This is in reasonable agreement with the measured value of $E_{a}=0.68 \pm 0.01 \mathrm{eV}$ for temperatures between $10^{\circ} \mathrm{C}$ and $70^{\circ} \mathrm{C} .33$ 
A similar analysis of the different defect contributions to the leakage current density was carried out for neutron irradiated detectors. Table IV shows the contributions of different defects to the leakage current density after a fluence of $1.5 \times 10^{13} \mathrm{n} / \mathrm{cm}^{2}$ and Fig. 6 compares the model calculation to measured data as a function of neutron fluence. For neutron damage, $\mathrm{V}_{2} \mathrm{O}$ and $\mathrm{V}_{2}$ states are predicted to dominate, but this time the total calculated leakage current is consistently underestimated by around two orders of magnitude.

\section{E. Possible explanations}

In summary, the model appears adequate but not perfect. Some minor reactions may still be missing and it is desirable that parameters, such as cross-sections and capture radii, are known with greater precision. The main effects of bulk damage, the change in effective doping and the leakage current increase, are predicted with reasonable accuracy for ${ }^{60} \mathrm{Co}$ gamma irradiated detectors. In contrast, significant differences are observed between experimental data and the model results for neutron irradiated devices; especially in the leakage current prediction. The model was therefore re-examined to try to shed light on the origin of this large discrepancy. Since only a few states appear to contribute significantly to leakage currents, the simplest procedure was to examine systematically each one to verify whether changes in assumed parameters could influence the result.

The two states which exercise the most influence over the results are $\mathrm{V}_{2} \mathrm{O}$ and $\mathrm{V}_{2}$ (see Tables III and IV). Most of the other contributions (from VO, VP, CC, etc.) would require such large changes in the assigned cross-sections that they can be ruled out. Very large underestimates of trap concentrations are not considered likely either; uncertainties are estimated to be around $40 \%$ at most. ${ }^{13}$ The CC and CO states were also excluded as culprits since these defects do not form during short irradiations with neutrons performed at temperatures below $\sim 10^{\circ} \mathrm{C}$, since the interstitial carbon atoms are essentially immobile, ${ }^{44}$ whereas large increases in leakage currents are still observed. ${ }^{28,45}$

It is possible, despite several decades of investigations into radiation induced defects in silicon, that not all traps created by neutrons have been identified and an unidentified state very close to the centre of the band-gap should contribute strongly to the leakage current. However the introduction rate of such a defect would have to be $\sim 8 \mathrm{~cm}^{-1}$ (assuming $\sigma=10^{-15} \mathrm{~cm}^{2}$ ) to account for all of the leakage current damage in neutron irradiated detectors. In this case its contribution to the effective doping concentration would also be very large in comparison with other charged defects. A donor would strongly compensate the effect of acceptor states such as $\mathrm{V}_{2} \mathrm{O}$, thereby worsening the discrepancy between the model and data for effective doping changes during neutron irradiation. Conversely, an acceptor with sufficiently high introduction rate would lead to 
type-inversion much sooner than observed. In addition the state must not be significantly produced during gamma irradiation.

The strong correlation ${ }^{11}$ between leakage current and effective doping suggests that a single mechanism might underlie the observations and the presence of defect clusters in neutron irradiated silicon, and their absence in gamma irradiated material, suggests a possible cause. The disordered regions must retain significant order because divacancies are readily identifiable in high concentration in DLTS studies. It seems plausible that the high $\mathrm{V}_{2}$ density in clusters could modify the normal SRH picture of generationrecombination. Recently, charge exchange reactions between traps have been observed 46,47 and enhanced diode currents attributed to this mechanism 48 . The investigation of this effect forms the subject of the remainder of this paper.

\section{EFFECT OF DIVACANCY CLUSTERING}

\section{A. Divacancy production and charge exchange reactions}

As already stressed, the main difference between fast neutron and gamma irradiations is the presence of clusters of damage from neutrons which are expected to be rich in $V_{2}$ states. With some simple assumptions the divacancy density in the terminal clusters can be estimated: the interaction cross section for neutrons on silicon in the few $\mathrm{MeV}$ range ${ }^{49}$ is approximately 3 barns and there are $5 \times 10^{22}$ atoms $/ \mathrm{cm}^{3}$, so the cluster introduction rate is $\AA 0.4 \mathrm{~cm}^{-1}$ if, on average, 2.5 terminal clusters are created per interacting neutron. 21,22 Assuming that all the $\mathrm{V}_{2}$ defects are distributed inside clusters, there are $\AA 12 \mathrm{~V}_{2}$ defects per cluster, with a local concentration of $\sim 10^{20} \mathrm{~V}_{2} / \mathrm{cm}^{3}$ if the clusters have an average volume 22 of $(50 \AA)^{3}$.

$\mathrm{V}_{2}$ defects are known to have three energy levels in the band gap, giving four charge states, (+, 0, -, or 2-) as in Fig. 7. The energy levels for the electrons associated with the charge states of (0), (-) and (2-) are at $\mathrm{E}_{\mathrm{V}}+0.25 \mathrm{eV}, \mathrm{E}_{\mathrm{c}}-0.42 \mathrm{eV}$ and $\mathrm{E}_{\mathrm{c}}-0.23 \mathrm{eV}$ respectively. 50 The states closest to the conduction or valence band edges have the highest carrier emission rate probabilities, with an exponential dependence on $E_{\text {band }}-E_{\text {trap. }}$. In high resistivity silicon under reverse bias, the neutral state of the divacancy is most probable, by a considerable amount. The $\mathrm{V}_{2}$ contribution to the leakage current can therefore be enhanced if the charge exchange reaction $V_{2}^{0}+V_{2}^{0} \rightarrow V_{2}^{+}+V_{2}^{-}$occurs.

Charge exchange reactions which influence the generation rate will also affect the occupancy of charged states since a new steady state situation will arise compared to a system of isolated defects. The enhancement of the number of charged states with higher 
emission probabilities not only generates more carriers into the conduction and valence bands, it also ensures that these states have a higher steady state concentration. This can therefore influence the effective doping concentration in a significant way.

This phenomenon is almost unique to the divacancy due to its multi-valent nature. In contrast, for identical single-level defects, the reaction $X^{0}+X^{0} \leftrightarrow X^{-}+X^{+}$cannot occur. $X$ cannot take on both positive and negative charge states and charge exchanges such as $\mathrm{X}^{0}+\mathrm{X}^{-} \leftrightarrow \mathrm{X}^{-}+\mathrm{X}^{0}$ do not influence the occupancy or carrier generation rate. For nonidentical single level states the reaction $X^{0}+Y^{-} \leftrightarrow X^{-}+Y^{0}$, for example, could enhance the generation rate if the energy level of $X$ is closer to the conduction band than the energy level of state Y. However, close proximity of non-identical defects is very unlikely in irradiated high resistivity silicon detectors since such defects are normally associated with impurities. Since the dominant impurity concentrations are $\sim 10^{15} \mathrm{~cm}^{-3}$, this places impurity related defects at least 100nm apart on average. An additional complexity, beyond the scope of this paper, is the possibility of other (unidentified) defects being present in the damage clusters. The inclusion of such defects would naturally modify the following calculations for clustered $\mathrm{V}_{2}$ occupancy and generation rate.

\section{B. Electron occupancy of the $\mathrm{V}_{2}$ levels.}

An example of electron and hole transitions and the corresponding transition rate formulae, ${ }^{51}$ between two general energy levels, $E_{1}$ and $E_{2}$, having electron occupancy $f_{1}$ and $f_{2}$, is shown schematically in Fig. 8. As in the standard SRH calculation for single levels, the thermal equilibrium case is considered in order to determine the emission rate probabilities which are then assumed to be unchanged in the steady state, nonequilibrium situation. For multi-valent states such as $\mathrm{V}_{2}$ the results of Shockley and Last 52 were used to determine the charge state occupancy in thermal equilibrium.

Although the reaction $\mathrm{V}_{2}^{0}+\mathrm{V}_{2}^{0} \rightarrow \mathrm{V}_{2}^{+}+\mathrm{V}_{2}^{-}$may dominate in typical conditions, all of the possible electron transfer reactions have been included in the model calculation for completeness. Only transitions between available states are considered; for example, only $\mathrm{V}_{2}$ defects already in the $(+)$ state can accept an electron to move into the $(0)$ state. Fig. 9 schematically illustrates the densities of states $N_{1}, N_{2}, N_{3}$ used to describe the set of $V_{2}$ defects in the cluster, and relates these values to the fraction of defects in each charge state $\left(\mathrm{N}_{+}, \mathrm{N}_{0}, \mathrm{~N}_{-}, \mathrm{N}_{2-}\right)$. Tables V and VI show how these densities of states were used in the rate formulae for the different electron emission and capture transitions. 
Under reverse bias, a silicon detector is in a steady state away from thermal equilibrium. The density of electrons and holes in each of the three $V_{2}$ energy levels is therefore constant. Considering the electron density gives,

$$
\frac{d n}{d t}=\frac{d n_{1}}{d t}=\frac{d n_{2}}{d t}=\frac{d n_{3}}{d t}=\frac{d p}{d t}=0
$$

where $\mathrm{n}_{1}, \mathrm{n}_{2}$ and $\mathrm{n}_{3}$ represent the electron density in the (-/2-), (0/-) and (+/0) divacancy levels respectively, and $\mathrm{n}$ and $\mathrm{p}$ are the free electron and hole concentrations. The electron occupancies of the different $\mathrm{V}_{2}$ levels can then be calculated by considering the different capture and emission reactions that may occur; considering the (0/-) level for example,

$$
\frac{d n_{2}}{d t}=r_{c(c \rightarrow 2)}+r_{c(1 \rightarrow 2)}+r_{e(3 \rightarrow 2)}+r_{e(v \rightarrow 2)}-r_{e(2 \rightarrow c)}-r_{e(2 \rightarrow 1)}-r_{c(2 \rightarrow 3)}-r_{c(2 \rightarrow v)}=0
$$

which in full gives

$$
\begin{aligned}
& f_{c} N_{c}\left(1-f_{2}\right) f_{3} N_{t}\left(1-f_{1}\right) f_{2} f_{3} N_{t}\left(1-f_{c}\right) N_{c} e^{-\Delta E_{c 2}} \\
&+f_{1} f_{2} f_{3} N_{t}\left(1-f_{2}\right) f_{3} N_{t}+\left(1-f_{1}\right) f_{2} f_{3} N_{t}\left(1-f_{1}\right) f_{2} f_{3} N_{t} e^{-\Delta E_{12}} \\
&+\left(1-f_{2}\right) f_{3} N_{t}\left(1-f_{2}\right) f_{3} N_{t} e^{-\Delta E_{23}}=+\left(1-f_{1}\right) f_{2} f_{3} N_{t}\left(1-f_{3}\right) N_{t} \\
&+f_{v} N_{v}\left(1-f_{2}\right) f_{3} N_{t} e^{-\Delta E_{2 v}}+\left(1-f_{1}\right) f_{2} f_{3} N_{t}\left(1-f_{v}\right) N_{v} \\
& \frac{f_{2}}{1-f_{2}}=k_{2}=\frac{f_{c} N_{c}+f_{1} f_{2} f_{3} N_{t}+\left(1-f_{2}\right) f_{3} N_{t} e^{-\Delta E_{23}}+f_{v} N_{v} e^{-\Delta E_{2 v}}}{\left.\left(1-f_{1}\right)\left\{\left(1-f_{c}\right) N_{c} e^{-\Delta E_{c 2}}+\left(1-f_{1}\right) f_{2} f_{3} N_{t} e^{-\Delta E_{12}}+\left(1-f_{3}\right) N_{t}+\left(1-f_{v}\right) N_{v}\right)\right\}}
\end{aligned}
$$

hence,

$$
f_{2}=\frac{k_{2}}{k_{2}+1}
$$

Similar expressions are obtained for the electron occupancies, $f_{1}$ and $f_{3}$, of the (-/2-) and $(+/ 0)$ divacancy levels respectively

$$
\begin{gathered}
f_{i}=\frac{k_{i}}{k_{i}+1} \\
k_{1}=\frac{f_{c} N_{c}+\left(1-f_{1}\right) f_{2} f_{3} N_{t} e^{-\Delta E_{12}}+\left(1-f_{2}\right) f_{3} N_{t} e^{-\Delta E_{13}}+f_{v} N_{v} e^{-\Delta E_{1 v}}}{\left(1-f_{c}\right) N_{c} e^{-\Delta E_{c 1}}+\left(1-f_{2}\right) f_{3} N_{t}+\left(1-f_{3}\right) N_{t}+\left(1-f_{v}\right) N_{v}} \\
k_{3}=\frac{f_{c} N_{c}+f_{1} f_{2} f_{3} N_{t}+f_{2} f_{3} N_{t}+f_{v} N_{v} e^{-\Delta E_{3 v}}}{\left(1-f_{2}\right)\left\{\left(1-f_{c}\right) N_{c} e^{-\Delta E_{c 3}}+\left(1-f_{1}\right) f_{2} f_{3} N_{t} e^{-\Delta E_{13}}+\left(1-f_{2}\right) f_{3} N_{t} e^{-\Delta E_{23}}+\left(1-f_{v}\right) N_{v}\right\}}
\end{gathered}
$$


where $N_{t}$ is the clustered $V_{2}$ density; $f_{C}$ and $f_{V}$ are the conduction band and valence band occupancy respectively (under reverse bias, $\mathrm{f}_{\mathrm{C}} \approx 0$ and $\mathrm{f}_{\mathrm{V}} \approx 1$ ). $\mathrm{N}_{\mathrm{C}}$ and $\mathrm{N}_{\mathrm{V}}$ are the densities of states in the conduction and valence bands respectively. Values of $\mathrm{N}_{\mathrm{c}}=6.0 \times 10^{19} \mathrm{~cm}^{-3}$ and $\mathrm{N}_{\mathrm{v}}=2.0 \times 10^{19} \mathrm{~cm}^{-3}$ (at $300 \mathrm{~K}$ ) were used in the calculations, consistent with $\mathrm{n}_{\mathrm{i}}=1.45 \times 10^{10} \mathrm{~cm}^{-3}$ at $300 \mathrm{~K}$ for a band gap of $1.12 \mathrm{eV} .53$ The abbreviation $\mathrm{EE}_{\mathrm{jk}}$ represents $\left(\mathrm{E}_{\mathrm{j}} \mathrm{E}_{\mathrm{k}}\right) / \mathrm{kT}$.

The equations for $f_{1}, f_{2}$ and $f_{3}$ were solved iteratively as a function of clustered $V_{2}$ density with the results shown in Fig. 10. The occupancy values $f_{1}$ and $f_{3}$ were close to zero and one respectively, consistent with the higher emission rates of these states. For clustered $V_{2}$ concentrations below $10^{15} \mathrm{~cm}^{-3}, \mathrm{f}_{2}$ is equal to the $\mathrm{SRH}$ occupancy prediction for a lone $\mathrm{V}_{2}$ state as the dominant interactions are between the (0/-) level and the conduction and valence bands. The above formula for $\mathrm{f}_{2}$ reduces to the usual SRH expression, as expected, when inter- $\mathrm{V}_{2}$ charge exchange reactions are suppressed. ${ }^{51}$ For clustered $V_{2}$ densities between $10^{15}$ and $10^{18} \mathrm{~cm}^{-3}$, the value of $f_{2}$ is then determined more by the dominant reaction $V_{2}^{0}+V_{2}^{0} \rightarrow V_{2}^{+}+V_{2}^{-}$and above $10^{18} \mathrm{~cm}^{-3}$ the values of $f_{1}, f_{2}$, and $f_{3}$ plateau since purely $\mathrm{V}_{2}$ transitions dominate, for example $\mathrm{V}_{2}^{+}+\mathrm{V}_{2}^{-} \rightarrow 2 \mathrm{~V}_{2}^{0}$ is more probable than the competing electron-hole generation reaction $\mathrm{V}_{2}^{+}+\mathrm{V}_{2}^{-} \rightarrow 2 \mathrm{~V}_{2}^{0}+\mathrm{e}^{-}+\mathrm{h}^{+}$involving the conduction and valence bands.

Fig. 11 illustrates the resulting fractions of $\mathrm{V}_{2}$ in the four different charge states. The ratio of $f_{2}$ to the SRH prediction for a single $V_{2}$ level at $E_{c}-0.42 e V$ is shown in Fig. 12. This mechanism of charge transfer between the $\mathrm{V}_{2}$ defects can therefore give rise to a large increase, up to 400 times the SRH value, in the number of $\mathrm{V}_{2}^{-}$states. With fewer $\mathrm{V}_{2}^{+}$states relative to $\mathrm{V}_{2}^{-}$, the increased number of charged acceptors due to the clustered $\mathrm{V}_{2}$ states will contribute to the effective doping concentration. For example, at the inversion fluence for $1 \mathrm{MeV}$ neutrons, $\left(\sim 2 \times 10^{13} \mathrm{n} / \mathrm{cm}^{2}\right)$, around $2 \times 10^{11} \mathrm{~cm}^{-3} \mathrm{~V}_{2}^{-}$states will be present in the bulk silicon, a similar value to $\left[\mathrm{V}_{2} \mathrm{O}^{-}\right]$and $\left[\mathrm{P}^{+}\right]$at this fluence. Therefore the clustering of $\mathrm{V}_{2}$ defects may be important in determining the change in $\mathrm{N}_{\text {eff }}$ in irradiated devices.

\section{Leakage current density and damage constant for clustered $V_{2}$ defects}

The leakage current density in the clusters $\mathrm{J}_{\mathrm{v}}^{\mathrm{cl}}$ due to the $\mathrm{V}_{2}$ states can also be determined from the steady state condition applied to the conduction band

$$
\frac{d n}{d t}=\frac{J_{v}^{c l}}{e}-\left(r_{e(1 \rightarrow c)}+r_{e(2 \rightarrow c)}+r_{e(3 \rightarrow c)}-r_{c(c \rightarrow 1)}-r_{c(c \rightarrow 2)}-r_{c(c \rightarrow 3)}\right)=0
$$


Neglecting capture terms that are suppressed under reverse bias, when $f_{c} \AA 0$ and $f_{v} \AA 1$ gives

$$
J_{v}^{c l}=e v \sigma N_{c} N_{t}\left(f_{1} f_{2} f_{3} e^{-\Delta E_{c 1}}+\left(1-f_{1}\right) f_{2} f_{3} e^{-\Delta E_{c 2}}+\left(1-f_{2}\right) f_{3} e^{-\Delta E_{c 3}}\right)
$$

The leakage current damage constant $\alpha^{\mathrm{cl}}$, (for the cluster contribution) can be expressed as

$$
\alpha^{c l}=\eta_{c l} J_{v}^{c l} V_{c l}
$$

where $\eta_{\mathrm{cl}}$ is the cluster introduction rate and $\mathrm{V}_{\mathrm{cl}}$ represents the volume of the terminal clusters. The damage constant can then be expressed in terms of the $V_{2}$ introduction rate $\eta_{\mathrm{V}_{2}}$, and the clustered $\mathrm{V}_{2}$ density $\mathrm{N}_{\mathrm{t}}$ as

$$
\alpha^{c l}=\frac{\eta_{V_{2}} J_{v}^{c l}}{N_{t}}
$$

From equation (15), the leakage current contribution from clustered $\mathrm{V}_{2}$ states is determined by the occupancy of the different $\mathrm{V}_{2}$ levels. Fig. 13 illustrates the results for $\mathrm{J}_{\mathrm{V}}^{\mathrm{cl}}$ as a function of the clustered $V_{2}$ concentration density. An increase in the slope of $J_{V}^{c l}$ with clustered $V_{2}$ density is observed as a result of the increase in $f_{2}$ at $N_{t} \AA 10^{15} \mathrm{~cm}^{-3}$. For $\mathrm{N}_{\mathrm{t}}<10^{15} \mathrm{~cm}^{-3}$, as with the occupancy values, $\mathrm{J}_{\mathrm{V}}^{\mathrm{cl}}$ is given by the standard SRH calculation for lone single level defects. The results of the model calculation of the leakage current damage constant are also shown in Fig. 13. For $V_{2}$ concentrations within the clusters greater than $\sim 10^{18} \mathrm{~cm}^{-3}$ the damage constant $\alpha^{\mathrm{cl}}$ has a value of $\sim 1 \times 10^{-16} \mathrm{~A} / \mathrm{cm}$ (at $300 \mathrm{~K}$ ), very similar to observed values of $1-2 \times 10^{-16} \mathrm{~A} / \mathrm{cm}$ (scaled to $300 \mathrm{~K}$ ). $4,5,28$ The temperature dependence of the leakage current contribution from clustered $V_{2}$ defects was also calculated for $\mathrm{N}_{\mathrm{t}}=10^{19} \mathrm{~cm}^{-3}$. It could be fitted with the usual form $\mathrm{Jv} \sim \mathrm{T}^{2} \exp \left(-\mathrm{E}_{\mathrm{a}} / \mathrm{kT}\right)$ with $\mathrm{E}_{\mathrm{a}}=0.60 \mathrm{eV}$, which compares well with the measured value of $0.62 \pm 0.02 \mathrm{eV} .31,32$

\section{SUMMARY}

Using a computational model of defect kinetics the evolution of different defect concentrations can be predicted for irradiated silicon with different initial impurity levels. With Shockley-Read-Hall semiconductor statistics included, the model predicts the value of observable parameters such as the effective doping concentration and leakage current density as a function of dose or fluence.

For ${ }^{60} \mathrm{Co}$ gamma irradiation, the model predictions for the change in effective doping, leakage current increases, and leakage current temperature dependence are in relatively 
good agreement with measured values. According to the model, these effects are dominated by the creation of $\mathrm{V}_{2} \mathrm{O}$ defects.

In the case of $1 \mathrm{MeV}$ neutron damage, $\mathrm{V}_{2} \mathrm{O}$ and $\mathrm{V}_{2}$ defects dominate the bulk damage effects but the agreement between the model and data is poor. In particular, the leakage current density is underestimated by around two orders of magnitude. This large discrepancy is unlikely to be due to uncertainties within the model and it is improbable that an unidentified state, near mid-gap, is responsible.

The clear difference between $1 \mathrm{MeV}$ neutron and ${ }^{60} \mathrm{Co}$ gamma damage is in the formation of dense defect clusters during neutron irradiation. Divacancies are estimated to be present in densities of $10^{20} \mathrm{~cm}^{-3}$ inside the clusters, in contrast to the other important defect species which tend to be distributed more uniformly throughout the bulk. For divacancies in such close proximity, charge exchange reactions such as $\mathrm{V}_{2}^{0}+\mathrm{V}_{2}^{0} \rightarrow \mathrm{V}_{2}^{+}+\mathrm{V}_{2}^{-}$may occur. These lead to an increase in the electron-hole pair generation rate and the concentration of charged divacancies by a factor of up to 400 over the SRH prediction. This mechanism could explain the large leakage current increases, and a significant fraction of the change in effective doping, observed in detectors irradiated with heavy particles such as neutrons.

\section{ACKNOWLEDGEMENTS}

Valuable discussions with Prof. G. Davies, Dr S. Watts and Dr J. Matheson are gratefully acknowledged, as is the financial support from UK PPARC.

${ }^{1}$ CMS Technical Proposal CERN/LHCC 94-38 (1994).

2 ATLAS Technical Proposal CERN/LHCC 94-43 (1994).

3 G. Hall, Reports on Progress in Physics 57, 481 (1994).

4 M. Edwards, G. Hall, and S. Sotthibandhu, Nucl. Instr. \& Meth. A310, 283 (1991).

5 K. Gill, G. Hall, S. Roe, S. Sotthibandhu, R. Wheadon, P. Giubellino, and L. Ramello, Nucl. Instr. \& Meth. A322, 177 (1992).

6 A. Holmes-Seidle, M. Robbins, S. Watts, P. Allport, R. Brenner, H.-G. Moser, S. Roe, J. Straver, P. Weilhammer, P. Chochula, I. Mikulec, S. Moszczynski, M. Turala, W. Dabrowski, P. Grybos, M. Idzik, D. Loukas, K. Misiakos, I. Siotis, K. Zachariadou, W. Dulinski, J. Michele, M Schaeffer, R. Turchetta, P. Booth, J. Richardson, N. Smith, K. Gill, G. Hall, R. Sachdeva, S. Sotthibandhu, D. Vitè, R. Wheadon, C. Arrighi, P. Delpierre, M.-C. Habrard, J.-C. Clemens, T. Mouthuy, B. S. Avset, L. Evensen, A. Hanneborg, T. A. Hansen, D. Bisello, A. Giraldo, A. Paccagnella, L. Kurchaninov, E. Spiriti, R. Apsimon, P. 
Guibellino, L. Ramello, W. L. Prado da Silva, M. Krammer, and M. Schuster, Nucl. Instr. \& Meth. A339, 511 (1994).

7 J. Matheson, H.-G. Moser, S. Roe, P. Weilhammer, S. Moszczynski, W. Dabrowski, P. Grybos, M. Idzik, A. Skoczen, K. Gill, G. Hall, B. MacEvoy, D. Vitè, R. Wheadon, P. Allport, C. Green, J. Richardson, R. Apsimon, L. Evensen, B. Avset, P. Guibellino, and L. Ramello, Nucl. Instr. \& Meth. A362, 297 (1995).

8 E. Fretwurst, H. Feick, M. Glaser, C. Gössling, E. H. M. Heijne, A. Hess, F. Lemeilleur, G. Lindström, K. H. Mählmann, A. Rolf, T. Schulz, and C. Soave, Nucl. Instr. \& Meth. A342, 119 (1994).

9 D. Pitzl, N. Cartiglia, B. Hubbard, D. Hutchinson, J. Leslie, K. O'Shaughnessy, W. Rowe, H. F.-W. Sadrozinski, A. Seiden, E. Spencer, H. J. Ziock, P. Ferguson, and W. F. Sommer, Nucl. Instr. \& Meth. A311, 98 (1992).

10 G. C. Messenger and M. S. Ash, The effects of radiation in electronic systems.

Van-Nostrand-Reinhold, New York (1986).

11 J. Matheson, M. Robbins, S. Watts, G. Hall, and B. MacEvoy, Nucl. Instr. \& Meth. A371, 575 (1996).

12 G. Davies, E. C. Lightowlers, R. C. Newman, and A. S. Oates, Semicond. Sci. Tech. 2, 524 (1987).

13 B. MacEvoy, G. Hall, and K. Gill, Nucl. Inst. \& Meth. A374, 12 (1996) and references therein.

14 G. Kinchin and S. Pease, Rep. Prog. Phys. Vol 18 (1955).

15 G. P. Summers, E. A. Burke, C. J. Dale, E. A. Wolicki, P. W. Marshall, and M. A. Gehlhausen, IEEE Trans. Nucl. Sci., Vol. 34, 1134 (1987).

16 O. S. Oen and D. K. Holmes, J. Appl. Phys. Vol 30, No. 8, 1289 (1959).

17 G. P. Summers, E. A. Burke, P. Shapiro, S. C. Messenger, and R. J. Walters, IEEE Trans. Nucl. Sci. Vol. 40, No. 6, 1372 (1993).

18 J. H. Cahn, J. Appl. Phys. Vol 30, No. 8, 1310 (1959).

19 J. Matheson, Private communication.

20 J. Lindhard, V. Nielson, M. Scharff, and P. V. Thomsen, Mat. Fys. Medd. Dan. Vid. Selsk. 33, No. 10 (1963).

21 G. P. Mueller, N. D. Wilsey, M. Rosen, IEEE Trans. Nucl. Sci., Vol 29, 1493 (1982).

21 V. A. J. van Lint, R. E. Leadon, and J. F. Colwell, IEEE Trans. Nucl. Sci., Vol 19, 181 (1972).

23 J. Matheson, M. Robbins, and S. Watts, RD20 Collaboration Technical Note. CERN $\mathrm{RD} 20 / \mathrm{TN} / 36$.

24 G. Watkins and J. Corbett, Phys Rev 138, A543 (1965).

25 B. Svennson and J. Lindström, J. Appl. Phys. Vol 72, No. 12, 5616 (1992).

26 V. Vinetskii and A. Kondrachuk, Rad. Eff., Vol. 30, 227 (1976).

27 T. Shi, D. X. Shen, F. M. Wu, and K. J. Cheng, J. Appl. Phys. Vol 67, No. 2, 1116 (1990). 
28 S. Sotthibandhu, PhD Thesis, Imperial College, 1994 (unpublished).

29 B. MacEvoy, Paper presented at the International Conference on Radiation Effects on Semiconductor Materials, Detectors and Devices, Florence, March 1996.

30 E. Fretwurst, H. Herdan, G. Lindström, U. Pein, M. Rollwagen, H. Schatz, P. Thomsen, and R. Wunsdorf, Nucl. Instr. \& Meth. A288, 1 (1990).

31 T. Ohsugi, A. Taketani, M. Noda, Y. Chiba, M. Asai, T. Kondo, T. Sato, M. Takasaki, K. H. Tanaka, K. Kondo, H. Hirayama, K. Yamamoto, and H. Tanaka, Nucl. Instr. \& Meth. A265, 105 (1988).

32 S. Bates, D. J. Munday, M. A. Parker, F. Anghinolfi, A. Chilingarov, A. Ciasnohova, M. Glaser, E. Heijne, P. Jarron, F. Lemeilleur, J. C. Santiard, R. Bonino, A. G. Clark, H. Kambara, C. Gössling, B. Lisowski, A. Rolf, S. Pilath, H. Feick, E. Fretwurst, G. Lindström, T. Schulz, R. A. Bardos, G. W. Gorfine, G. F. Moorhead, G. N. Taylor, and S. N. Tovey, Nucl. Instr. \& Meth. A 344, 228 (1994).

33 B. MacEvoy, PhD Thesis, Imperial College, 1996 (unpublished).

34 S. Bates, Presentation given at 2nd International Conference on Large Scale Applications and Radiation Hardness of Semiconductors, Florence, May 1995.

35 H.-J. Ziock, K. Holzcheiter, A. Morgan, A. P. T. Palounek, J. Ellison, A. P. Heinson, M. Mason, S. J. Wimpenny, E. Barberis, N. Cartiglia, A. Grillo, K. O'Shaughnessy, J. Rahn, P. Ringaldi, W. A. Rowe, H. F.-W. Sadroxinski, A. Seiden, E. Spencer, A. Webster, R. Wichmann, M. Wilder, M. A. Frautschi, J. A. J. Matthews, D. McDonald, D. Skinner, D. Coupal and T. Pal, Nucl. Instr. \& Meth. A342, 96 (1994).

36 W. Shockley and W. T. Read, Phys. Rev., Vol. 87, No. 5, 835 (1952).

37 R. Hall, Phys. Rev., Vol. 87, 387 (1952).

38 Y. Lee, T. D. Bilash and J. Corbett, Rad. Eff. 29, 7 (1976).

39 Y. Lee and J. Corbett, Phys. Rev. B13, 2653 (1976).

40 SINTEF, Postboks 2, 124 Blindern, 0314 Oslo 3, Norway.

41 Micron Semiconductor Limited, Lancing, England.

42 M. Edwards and D. Perry. Rutherford Appleton Laboratory Report, RAL-90-065.

43 V. Alex, S. Finkbeiner, and J. Weber, J. Appl. Phys. Vol. 79, No. 9, 69 (1996).

44 R. A. Woolley, E. C. Lightowlers, A. K. Tipping, M. C. Claybourn, and R. C. Newman, Mater. Sci. Forum 10-12, 929 (1986).

45 F. Lemeilleur, S.J. Bates, A. Chilingarov, C. Furetta, M. Glaser, E.H.M. Heijne, P. Jarron, C. Leroy, C Soave, and I. Trigger, Nucl. Instr. and Meth. A360, 438 (1995).

46 W. M. Chen, B. Monemar, E. Janzén, and J. L. Lindström, Phys. Rev. Lett. Vol 67, No. 14, 1914 (1991).

47 A. Frens, M. T. Bennebroek, A. Zakrzewski, J. Schmidt, W. M. Chen, E. Janzén, and J. L. Lindström, and B. Monemar, Phys. Rev. Lett. Vol 72, No. 18, 2939 (1994).

48 A. Schenk and U. Krumbein, J. Appl. Phys. Vol 78, No. 5, 3185 (1995). 
49 D. I. Garber and R. R. Kinsey, Neutron Cross Sections, Vol. 2, Curves, National Neutron Cross Section Center, Brookhaven Laboratory.

50 B. G. Svennson, B. Mohadjeri, A. Hallén, J. H. Svensson, J. W. Corbett, Phys. Rev. B Vol 43, No. 9, 2292 (1991) and references therein.

51 K. Gill, G. Hall and B. MacEvoy, CMS Technical Note, CERN/CMS/TN/96-017.

52 W. Shockley and J. Last, Phys. Rev. Vol 107, No. 2, 392 (1957).

53 S. Sze. Semiconductor Devices, Physics and Technology. John Wiley \& Sons, and references therein. 
TABLE I. Defect states and energy levels considered in the modelling procedure. The $\cosh (\beta)$ factors relate to the formula for the generation rate; values are approximate. A smaller $\cosh (\beta)$ factor implies a larger leakage current contribution.

\begin{tabular}{|c|c|c|c|}
\hline Defect identity & Energy level & defect type & $\cosh (\beta)$ \\
\hline $\mathrm{VO}$ & $\mathrm{E}_{\mathrm{C}}-0.17$ & acceptor & $3 \times 10^{6}$ \\
\hline $\mathrm{V}_{2} \mathrm{O}$ & $\mathrm{E}_{\mathrm{C}}-0.50$ & acceptor & 4 \\
\hline $\mathrm{V}_{2}$ & $\mathrm{E}_{\mathrm{C}}-0.23$ & acceptor & $(-)$ \\
& $\mathrm{E}_{\mathrm{C}}-0.42$ & acceptor & 200 \\
& $\mathrm{E}_{\mathrm{V}}+0.25$ & donor & $(-)$ \\
\hline $\mathrm{VP}$ & $\mathrm{E}_{\mathrm{C}}-0.45$ & acceptor & 70 \\
\hline $\mathrm{CC}$ & $\mathrm{E}_{\mathrm{C}}-0.17$ & acceptor & $3 \times 10^{6}$ \\
\hline $\mathrm{CO}$ & $\mathrm{E}_{\mathrm{V}}+0.36$ & donor & 700 \\
\hline
\end{tabular}

TABLE II. Defect reactions included in the simulation.

Primary reactions (in the PKA cluster)

\begin{tabular}{|l|l|l|}
\hline I reactions & V reactions & $C_{i}$ reactions \\
\hline $\mathrm{I}+\mathrm{V} \rightarrow \mathrm{Si}$ & $\mathrm{V}+\mathrm{V} \rightarrow \mathrm{V}_{2}$ & $\ldots$. \\
\hline
\end{tabular}

Diffusion reactions

\begin{tabular}{|l|l|l|}
\hline I reactions & V reactions & $C_{i}$ reactions \\
\hline $\mathrm{I}+\mathrm{C}_{\mathrm{s}} \rightarrow \mathrm{C}_{\mathrm{i}}$ & $\mathrm{V}+\mathrm{V} \rightarrow \mathrm{V}_{2}$ & $\mathrm{C}_{\mathrm{i}}+\mathrm{C}_{\mathrm{s}} \rightarrow \mathrm{CC}$ \\
$\mathrm{I}+\mathrm{CC} \rightarrow \mathrm{CCI}$ & $\mathrm{V}+\mathrm{V}_{2} \rightarrow \mathrm{V}_{3}$ & $\mathrm{C}_{\mathrm{i}}+\mathrm{O} \rightarrow \mathrm{CO}$ \\
$\mathrm{I}+\mathrm{CCI} \rightarrow \mathrm{CCII}$ & $\mathrm{V}+\mathrm{O} \rightarrow \mathrm{VO}$ & \\
$\mathrm{I}+\mathrm{CO} \rightarrow \mathrm{COI}$ & $\mathrm{V}+\mathrm{VO} \rightarrow \mathrm{V}_{2} \mathrm{O}$ & \\
$\mathrm{I}+\mathrm{COI} \rightarrow \mathrm{COII}$ & $\mathrm{V}+\mathrm{P} \rightarrow \mathrm{VP}$ & \\
$\mathrm{I}+\mathrm{VO} \rightarrow \mathrm{O}$ & & \\
$\mathrm{I}+\mathrm{V}_{2} \rightarrow \mathrm{V}$ & & \\
$\mathrm{I}+\mathrm{VP} \rightarrow \mathrm{P}$ & & \\
\hline
\end{tabular}


TABLE III. Calculated current contributions after $100 \mathrm{Mrad}{ }^{60} \mathrm{Co}$, compared with the interpolated data value at $100 \mathrm{Mrad}(\mathrm{T}=300 \mathrm{~K})$.

\begin{tabular}{|c|c|c|}
\hline Defect identity & $\begin{array}{c}\text { Concentration } \\
\left(\mathrm{cm}^{-3}\right)\end{array}$ & $\begin{array}{c}\text { Contribution to } \mathrm{J}_{\mathrm{V}} \\
\left(\mu \mathrm{A} / \mathrm{cm}^{3}\right)\end{array}$ \\
\hline $\mathrm{VO}$ & $1.6 \times 10^{14}$ & $5.6 \times 10^{-4}$ \\
\hline $\mathrm{V}_{2} \mathrm{O}$ & $2.8 \times 10^{13}$ & 71 \\
\hline $\mathrm{V}_{2}$ & $6.1 \times 10^{12}$ & 0.33 \\
\hline $\mathrm{VP}$ & $2.5 \times 10^{11}$ & 0.041 \\
\hline $\mathrm{CC}$ & $1.1 \times 10^{14}$ & $3.9 \times 10^{-4}$ \\
\hline $\mathrm{CO}$ & $4.2 \times 10^{13}$ & 0.74 \\
\hline \multirow{2}{*}{} & total predicted current density: $\Sigma\left(\mathrm{J}_{\mathrm{V}}\right)=72 \mu \mathrm{A} / \mathrm{cm}^{3}$ \\
\cline { 2 - 3 } & \multicolumn{2}{|c|}{ observed value: $\mathrm{J}_{\mathrm{V}}=40 \mu \mathrm{A} / \mathrm{cm}^{3}$} \\
\cline { 2 - 3 }
\end{tabular}

TABLE IV. Calculated current contributions after $1.5 \times 10^{13} \mathrm{n} / \mathrm{cm}^{2}$, compared with the expected value based on $\alpha=10^{-16} \mathrm{~A} / \mathrm{cm}(\mathrm{T}=300 \mathrm{~K})$.

\begin{tabular}{|c|c|c|}
\hline Defect identity & $\begin{array}{c}\text { Concentration } \\
\left(\mathrm{cm}^{-3}\right)\end{array}$ & $\begin{array}{c}\text { Contribution to } \mathrm{J}_{\mathrm{v}} \\
\left(\mu \mathrm{A} / \mathrm{cm}^{3}\right)\end{array}$ \\
\hline $\mathrm{VO}$ & $4.6 \times 10^{13}$ & $1.6 \times 10^{-4}$ \\
\hline $\mathrm{V}_{2} \mathrm{O}$ & $1.6 \times 10^{12}$ & 3.8 \\
\hline $\mathrm{V}_{2}$ & $5.8 \times 10^{13}$ & 3.1 \\
\hline $\mathrm{VP}$ & $1.1 \times 10^{11}$ & 0.018 \\
\hline $\mathrm{CC}$ & $9.3 \times 10^{13}$ & $3.2 \times 10^{-4}$ \\
\hline $\mathrm{CO}$ & $3.3 \times 10^{13}$ & 0.58 \\
\hline \multirow{2}{*}{} & total predicted current density: $\Sigma\left(\mathrm{J}_{\mathrm{v}}\right)=7.5 \mu \mathrm{A} / \mathrm{cm}^{3}$ \\
\cline { 2 - 3 } & \multicolumn{2}{|c|}{ observed value: $\mathrm{J}_{\mathrm{V}}=1.5 \mathrm{~mA} / \mathrm{cm}^{3}$} \\
\cline { 2 - 3 }
\end{tabular}


TABLE V. Levels and density of states involved in the different electron capture transitions allowed in the $\mathrm{V}_{2}$ cluster.

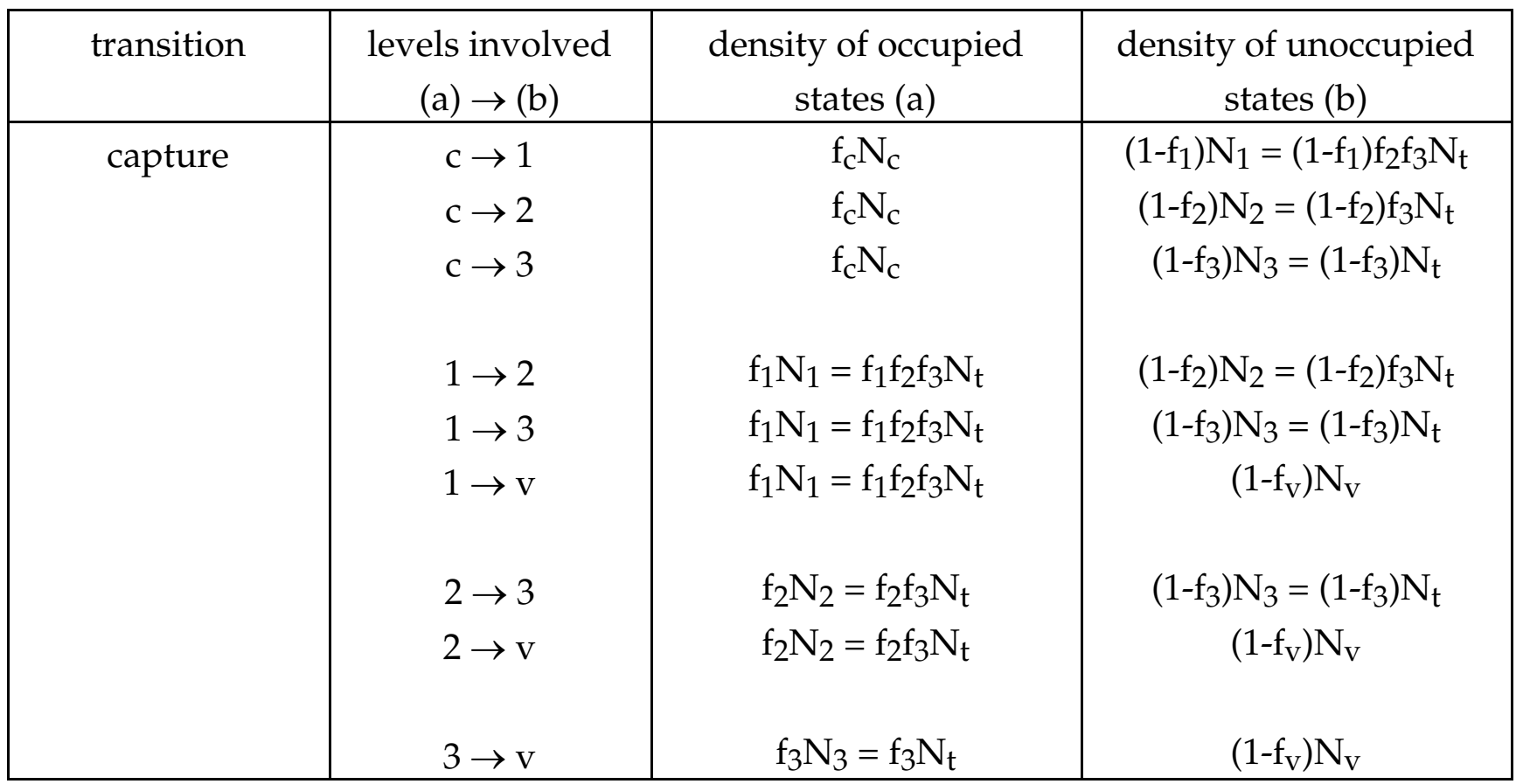

Table VI. Levels and density of states involved in the different electron emission transitions allowed in the $V_{2}$ cluster.

\begin{tabular}{|c|c|c|c|}
\hline transition & $\begin{array}{c}\text { levels involved } \\
(\mathrm{a}) \rightarrow(\mathrm{b})\end{array}$ & $\begin{array}{c}\text { density of occupied } \\
\text { states }(\mathrm{a})\end{array}$ & $\begin{array}{c}\text { density of unoccupied } \\
\text { states }(\mathrm{b})\end{array}$ \\
\hline emission & $\mathrm{v} \rightarrow 3$ & $\mathrm{f}_{\mathrm{v}} \mathrm{N}_{\mathrm{v}}$ & $\left(1-\mathrm{f}_{3}\right) \mathrm{N}_{3}=\left(1-\mathrm{f}_{3}\right) \mathrm{N}_{\mathrm{t}}$ \\
$\mathrm{v} \rightarrow 2$ & $\mathrm{f}_{\mathrm{v}} \mathrm{N}_{\mathrm{v}}$ & $\left(1-\mathrm{f}_{2}\right) \mathrm{N}_{2}=\left(1-\mathrm{f}_{2}\right) \mathrm{f}_{3} \mathrm{~N}_{\mathrm{t}}$ \\
& $\mathrm{f}_{\mathrm{V}} \mathrm{N}_{\mathrm{v}}$ & & $\left(1-\mathrm{f}_{1}\right) \mathrm{N}_{1}=\left(1-\mathrm{f}_{1}\right) \mathrm{f}_{2} \mathrm{f}_{3} \mathrm{~N}_{\mathrm{t}}$ \\
& $\mathrm{v} \rightarrow 1$ & $\left(1-\mathrm{f}_{2}\right) \mathrm{f}_{3} \mathrm{~N}_{3}=\left(1-\mathrm{f}_{2}\right) \mathrm{f}_{3} \mathrm{~N}_{\mathrm{t}}$ & $\left(1-\mathrm{f}_{2}\right) \mathrm{N}_{2}=\left(1-\mathrm{f}_{2}\right) \mathrm{f}_{3} \mathrm{~N}_{\mathrm{t}}$ \\
& $3 \rightarrow 2$ & $\left(1-\mathrm{f}_{2}\right) \mathrm{f}_{3} \mathrm{~N}_{3}=\left(1-\mathrm{f}_{2}\right) \mathrm{f}_{3} \mathrm{~N}_{\mathrm{t}}$ & $\left(1-\mathrm{f}_{1}\right) \mathrm{N}_{1}=\left(1-\mathrm{f}_{1}\right) \mathrm{f}_{2} \mathrm{f}_{3} \mathrm{~N}_{\mathrm{t}}$ \\
& $3 \rightarrow 1$ & $\left(1-\mathrm{f}_{2}\right) \mathrm{f}_{3} \mathrm{~N}_{3}=\left(1-\mathrm{f}_{2}\right) \mathrm{f}_{3} \mathrm{~N}_{\mathrm{t}}$ & $\left(1-\mathrm{f}_{\mathrm{c}}\right) \mathrm{N}_{\mathrm{c}}$ \\
& $3 \rightarrow \mathrm{c}$ & & \\
& $2 \rightarrow 1$ & $\left(1-\mathrm{f}_{1}\right) \mathrm{f}_{2} \mathrm{~N}_{2}=\left(1-\mathrm{f}_{1}\right) \mathrm{f}_{2} \mathrm{f}_{3} \mathrm{~N}_{\mathrm{t}}$ & $\left(1-\mathrm{f}_{1}\right) \mathrm{N}_{1}=\left(1-\mathrm{f}_{1}\right) \mathrm{f}_{2} \mathrm{f}_{3} \mathrm{~N}_{\mathrm{t}}$ \\
& $2 \rightarrow \mathrm{c}$ & $\left(1-\mathrm{f}_{1}\right) \mathrm{f}_{2} \mathrm{~N}_{2}=\left(1-\mathrm{f}_{1}\right) \mathrm{f}_{2} \mathrm{f}_{3} \mathrm{~N}_{\mathrm{t}}$ & $\left(1-\mathrm{f}_{\mathrm{c}}\right) \mathrm{N}_{\mathrm{c}}$ \\
& $1 \rightarrow \mathrm{c}$ & $\mathrm{f}_{1} \mathrm{~N}_{1}=\mathrm{f}_{1} \mathrm{f}_{2} \mathrm{f}_{3} \mathrm{~N}_{\mathrm{t}}$ & $\left(1-\mathrm{f}_{\mathrm{c}}\right) \mathrm{N}_{\mathrm{c}}$ \\
& & & \\
& & & \\
& & &
\end{tabular}



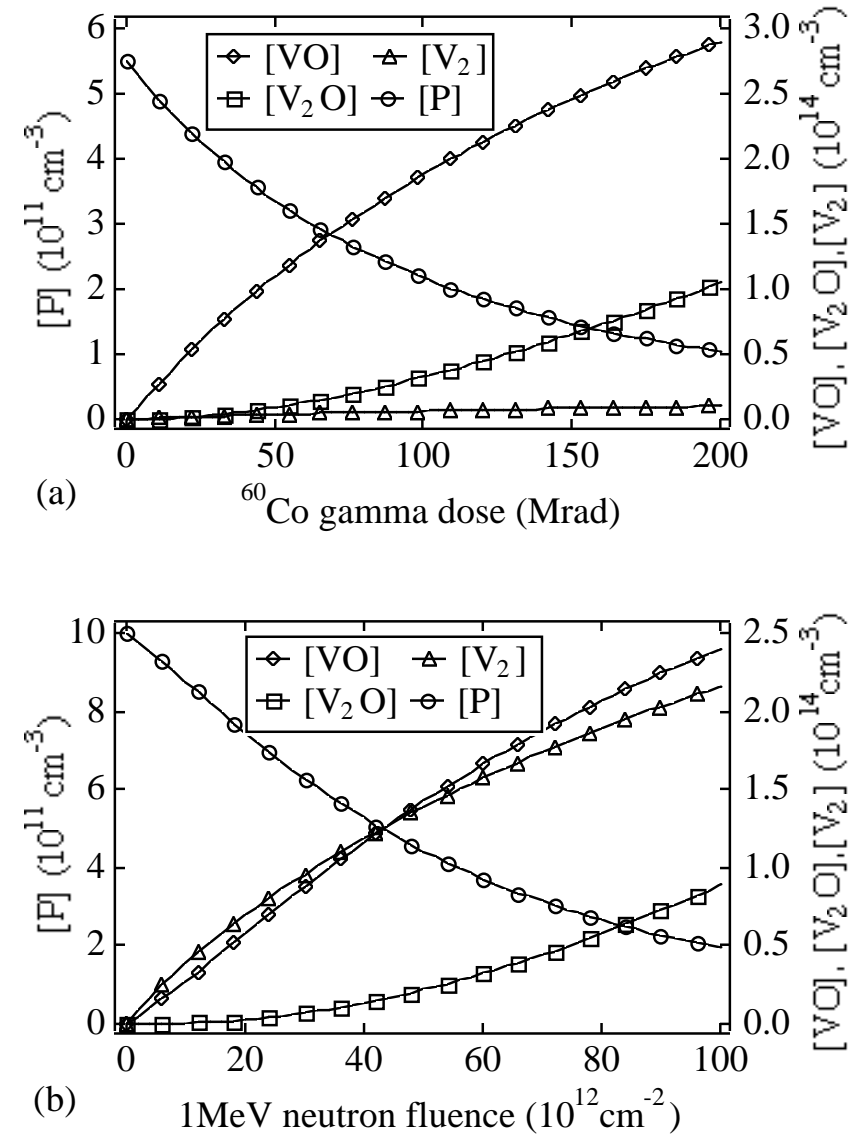

Figure 1: Modelled evolution of different defect and phosphorus dopant concentration with (a) ${ }^{60}$ Co gamma dose, and (b) $1 \mathrm{MeV}$ neutron fluence. 


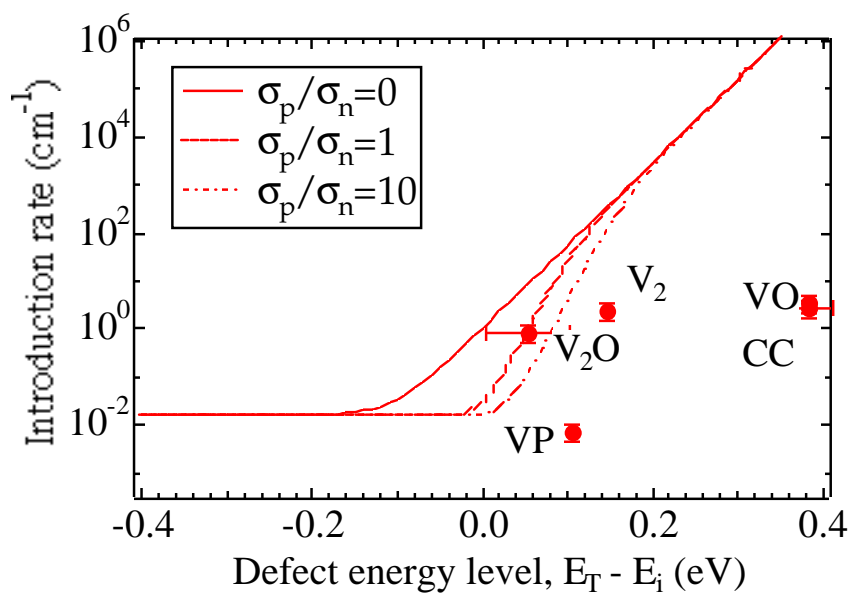

Figure 2: Introduction rate required in order to account for observed changes in effective doping due to bulk damage from neutrons for acceptor states with different energy levels. The $\mathrm{V}_{2} \mathrm{O}$ defect state stands out as the most probable candidate for the deep-acceptor state responsible for the observed effects. See ref [11] for details of the calculations. 


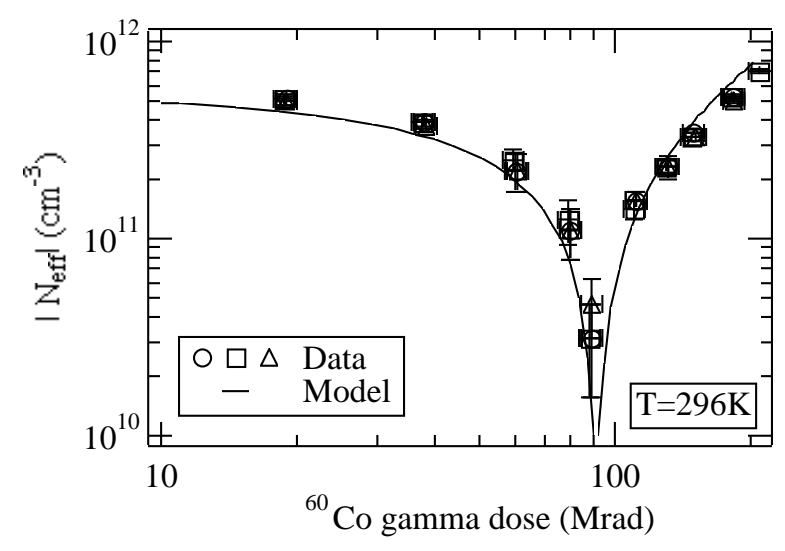

Figure 3: Data and calculation for change of effective doping concentration with ${ }^{60} \mathrm{Co}$ gamma dose.

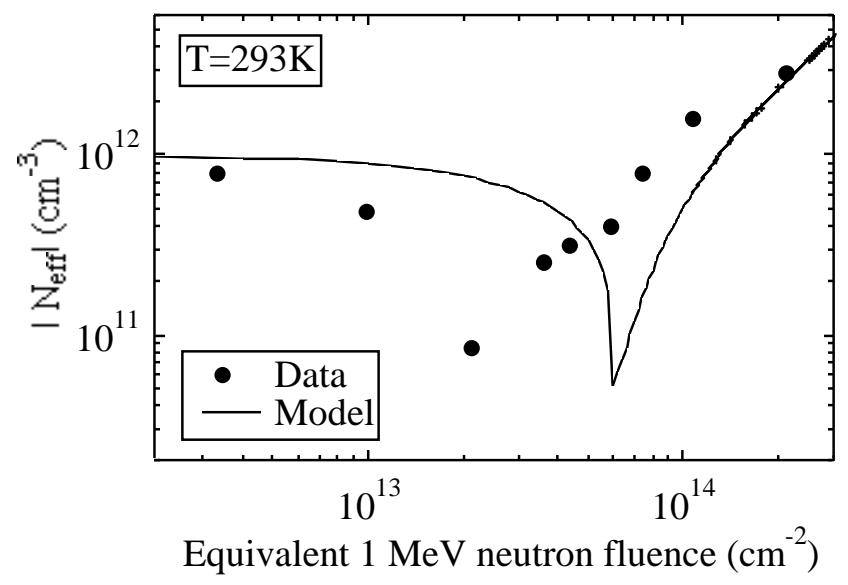

Figure 4: Data and calculation for evolution of effective doping concentration with $1 \mathrm{MeV}$ neutron fluence. 


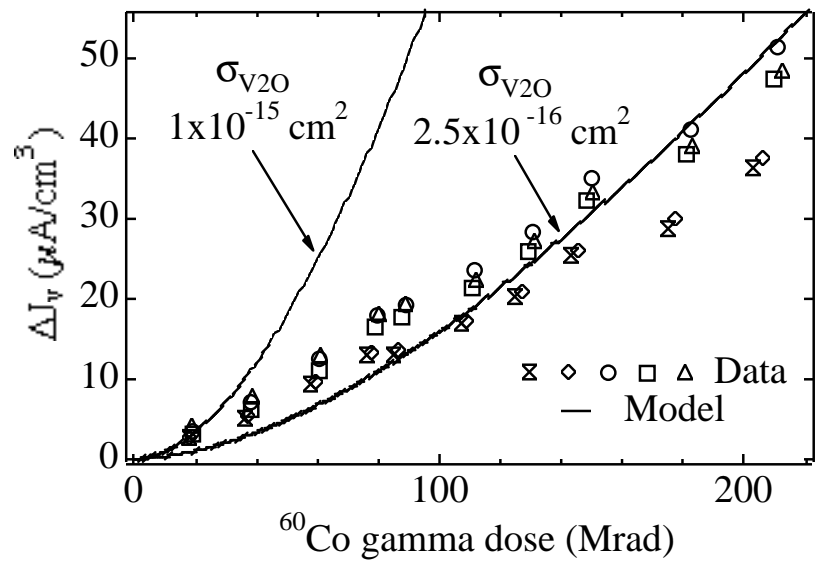

Figure 5: Data and calculated leakage current density in silicon detectors irradiated with ${ }^{60} \mathrm{Co}$ photons. Two curves are shown for the model prediction illustrating that the probable $\mathrm{V}_{2} \mathrm{O}$ carrier capture cross-section is $\sim 2.5 \times 10^{-16} \mathrm{~cm}^{2}$.

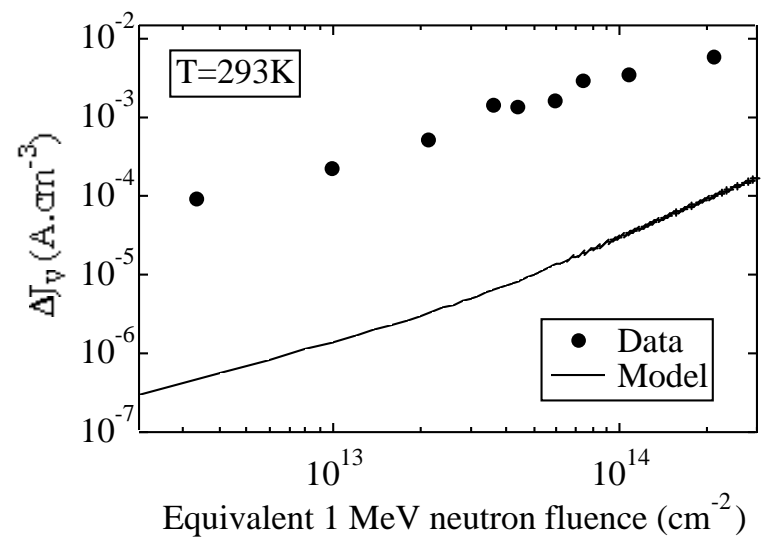

Figure 6: Data and calculated leakage current density in silicon diodes irradiated with $1 \mathrm{MeV}$ neutrons. 


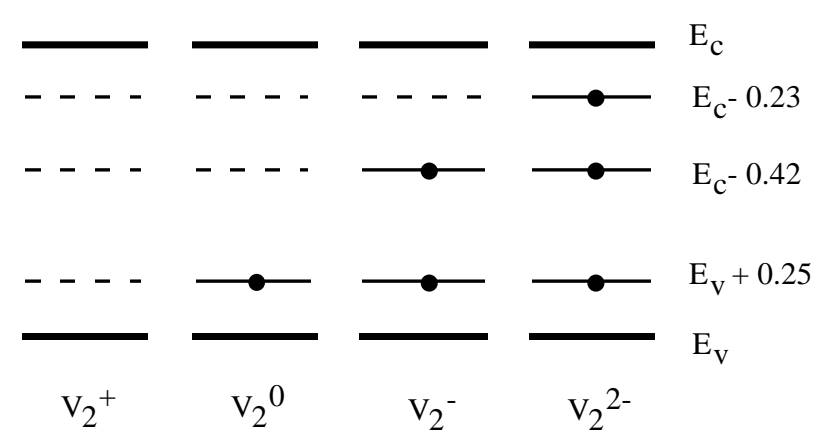

Figure 7: The four divacancy charge states, corresponding to different electron occupancies of the defect.

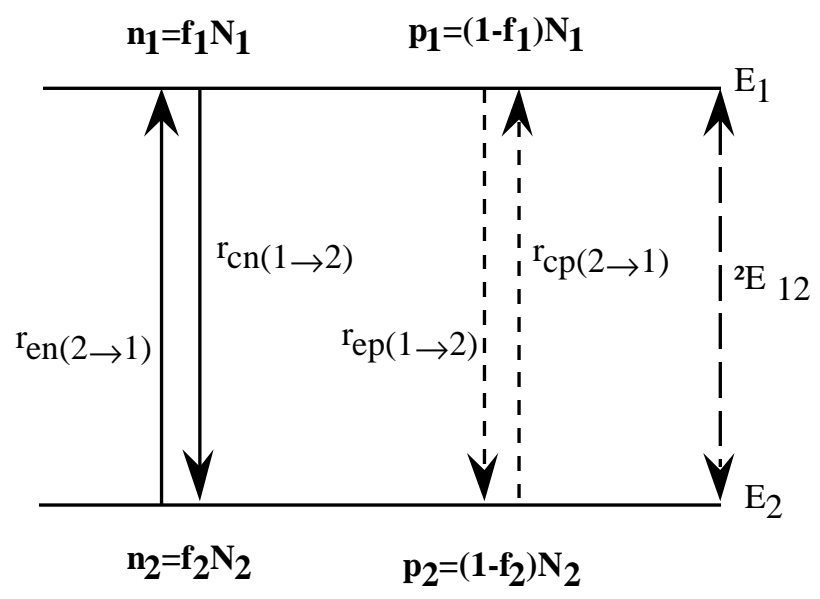

electron transfer rates

$$
\begin{aligned}
& \text { emission: } r_{e n(2 \rightarrow 1)}=v_{t h} \sigma_{n} f_{2} N_{2}\left(1-f_{1}\right) N_{1} e^{-\Delta E_{12} / k T} \\
& \text { capture: } r_{c n(1 \rightarrow 2)}=v_{t h} \sigma_{n} f_{1} N_{1}\left(1-f_{2}\right) N_{2} \\
& \text { hole transfer rates } \\
& \text { emission: } r_{e p(1 \rightarrow 2)}=v_{t h} \sigma_{p}\left(1-f_{1}\right) N_{1} f_{2} N_{2} e^{-\Delta E_{12} / k T} \\
& \text { capture: } r_{c p(2 \rightarrow 1)}=v_{t h} \sigma_{n}\left(1-f_{2}\right) N_{2} f_{1} N_{1}
\end{aligned}
$$

Figure 8: Electron and hole transitions between two different energy levels in the forbidden gap and the corresponding rates of emission and capture. 


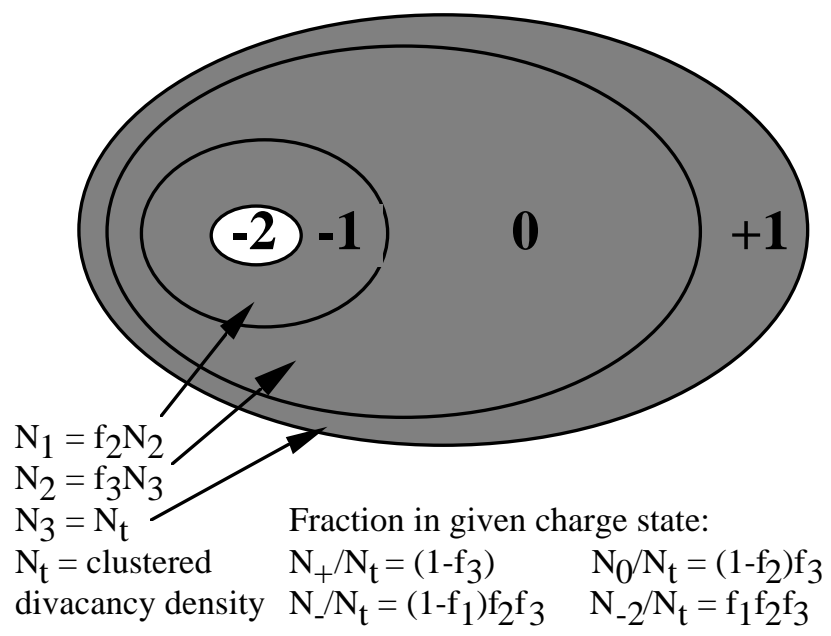

Figure 9: Densities of interacting $\mathrm{V}_{2}$ states in the $\mathrm{V}_{2}$ clusters and relationship with fraction of defects in different charge states.

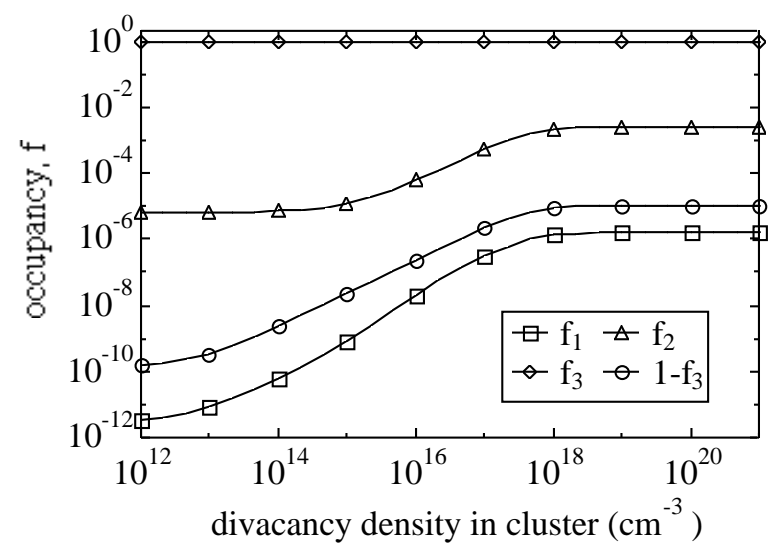

Figure 10: Occupancy of the different energy levels in the $\mathrm{V}_{2}$ clusters. For clarity, the value of $\left(1-f_{3}\right)$ is also included on the graph.

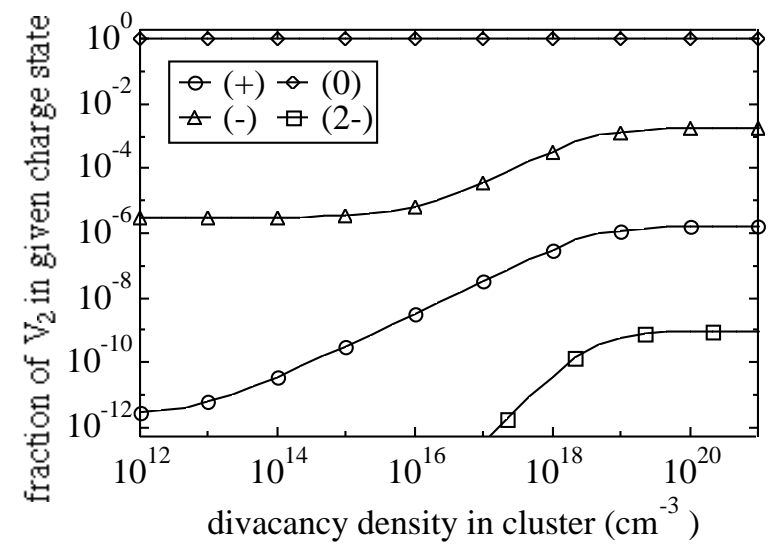

Figure 11: Fraction of clustered $V_{2}$ defects in each charge state. 


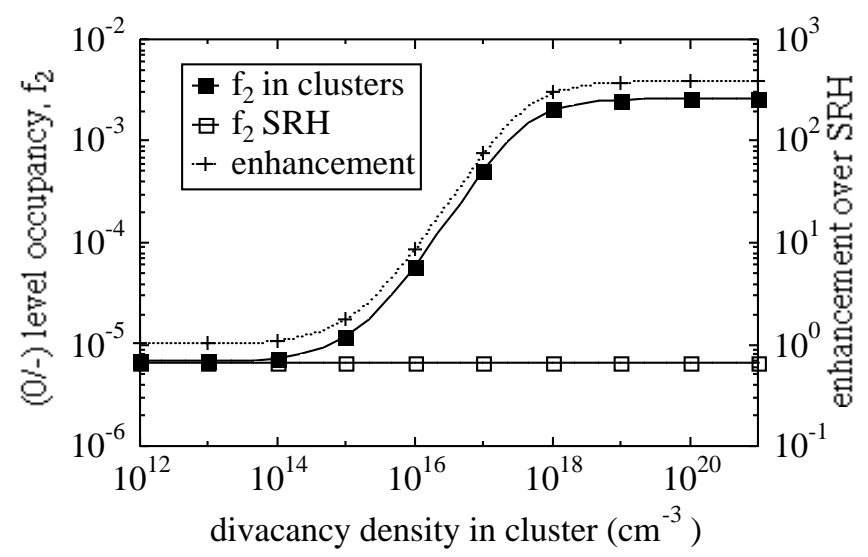

Figure 12: Enhancement of the occupancy $f_{2}$ of the (0/-) level for clustered $V_{2}$ defects compared to the standard SRH calculation for isolated $\mathrm{V}_{2}$ defects.

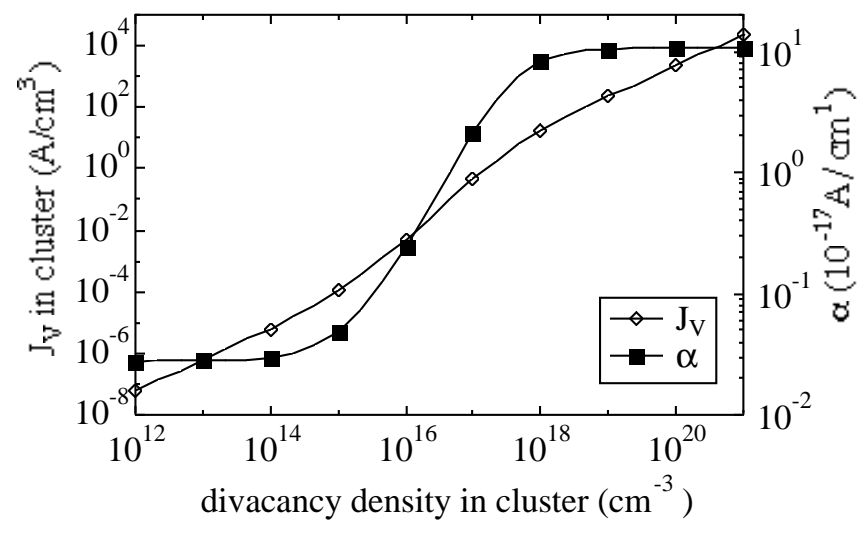

Figure 13: Leakage current density generated in $\mathrm{V}_{2}$ clusters and contribution to leakage current damage constant. 